\title{
Tracing magma emplacement processes by microstructural and mineral compositional variations: an example from the Unit 7-8 boundary zone of the Rum Layered Intrusion, NW Scotland \\ FELIX E.D. KAUFMANN ${ }^{1}$, BRIAN O'DRISCOLL ${ }^{2}$ AND LUTZ HECHT $^{1}$ \\ ${ }^{1}$ Museum für Naturkunde Berlin \\ ${ }^{2}$ University of Manchester \\ Presenting Author: Felix.Kaufmann@mfn.berlin
}

The Rum Layered Intrusion, located on the Isle of Rum in NW Scotland, represents an excellent natural laboratory to study various magmatic processes like cumulate formation, magma solidification and post-magmatic re-equilibration. The $\sim 60 \mathrm{Ma}$ old intrusion is particularly suitable due to its relatively young age and small size, meaning it has not undergone significant post-emplacement alteration. Here, we present detailed field observations together with microstructural and mineral chemical analyses for the Unit 7-8 boundary rock package of the Eastern Layered Suite to better understand the processes that drive the formation of layered intrusions.

In general terms, the Unit 7-8 boundary sequence comprises the Unit 7 troctolite footwall, overlain by a $1-20 \mathrm{~cm}$ thick layer of anorthosite, the 1-3 mm thick main $\mathrm{Cr}$-spinel seam and the Unit 8 feldspathic peridotite on top. Cr-spinel and plagioclase composition varies systematically along strike, suggesting a spatially controlled formation process. Plagioclase primocrysts in the anorthosite layer typically show normal zoning with REE enriched rims. Plagioclase in the footwall troctolite and the anorthosite layer exhibits similar microstructural characteristics such as grainsize frequency distribution and relative constant alignment factors, indicating a similar origin. Based on our combined observations we propose that the Unit 7-8 seam package and its lateral variations formed during a multi-stage magma replenishment event involving significant interaction of the replenishing magma with the existing crystal mush. Specifically, the anorthosite layer represents a restitic layer, formed from the Unit 7 troctolite crystal mush by thermal erosion and dissolution due to infiltrating magma. Subsequent dissolution of the anorthosite layer by new replenishing magma led to peritectic in-situ crystallisation of the Cr-spinel seam, with continued magma input eventually producing the overlying Unit 8 peridotite. Finally, we consider dendritic elemental zoning pattern measured in olivines of the Unit 8 peridotite help to further constrain the cooling history of the Rum Layered Intrusions. Specifically, dendritic P zonation in olivine could suggest rapid undercooling of the intruding magmas and diffusion-controlled crystal growth. Such undercooling was also likely responsible for the systematic lateral changes in mineral chemistry. 